\title{
Structured Graded Lung Rehabilitation for Children with Mechanical Ventilation
}

\author{
Lei Ren ${ }^{1}$, Jing $\mathrm{Hu}^{2}$, Mei $\mathrm{Li}^{1, *}$, Ling $\mathrm{Zhang}^{2}$ and Jinyue $\mathrm{Xia}^{3}$ \\ ${ }^{1}$ Department of Nursing, Children's Hospital of Nanjing Medical University, Nanjing, 210008, China \\ ${ }^{2}$ Department of rehabilitation medicine, Children's Hospital of Nanjing Medical University, Nanjing, 210008, China \\ ${ }^{3}$ International Business Machines Corporation (IBM), NY, USA \\ *Corresponding Author: Mei Li. Email: limeilimei6868@126.com \\ Received: 15 March 2021; Accepted: 01 May 2021
}

\begin{abstract}
Lung rehabilitation is safe and feasible, and it has positive benefits in weaning the machine as soon as possible, shortening the time of hospitalization and improving the prognosis of children with mechanical ventilation. However, at present, the traditional medical concept is deep-rooted, and doctors' understanding of early rehabilitation is inadequate. It is necessary to make in-depth exploration in the relevant guidelines and expert consensus to formulate standardized early rehabilitation diagnosis and treatment procedures and standards for mechanically ventilated children. In the paper, a structured graded lung rehabilitation program is constructed for children with mechanical ventilation to improve their respiratory function, shorten the time of mechanical ventilation and pediatric intensive care unit (PICU) hospitalization, and reduce their anxiety, based on the principal component analysis of functional pneumonia data. Scientific evaluation and dynamic monitoring ensure the safety of the implementation of the program and promote the prognosis and prognosis of the disease. The proposed lung rehabilitation program provides a reference basis for the formulation of lung rehabilitation guidelines for children with mechanical ventilation. And It has important reference significance for clinical pulmonary rehabilitation to alleviate the concerns of clinicians and lay the foundation for the large-scale promotion of early lung rehabilitation.
\end{abstract}

Keywords: Lung rehabilitation; mechanical ventilation; principal component analysis

\section{Introduction}

Mechanical ventilation is one of the important measures to treat critically ill children. It has been reported that about $30 \%$ of children in the pediatric intensive care unit (PICU) receive mechanical ventilation [1,2]. The Mechanical ventilation techniques also carry a series of problems while saving more lives, such as ventilator-associated pneumonia, post-ICU syndrome (PICS), and decreased respiratory function [3,4]. Among them, respiratory function decline is the most insidious, indirectly manifested as prolonged mechanical ventilation, difficulty in weaning, and secondary intubation after weaning. Wang et al. [5] reported that $41.7 \%$ of the children retained in PICU had difficulty in weaning

This work is licensed under a Creative Commons Attribution 4.0 International License, which permits unrestricted use, distribution, and reproduction in any medium, provided the original work is properly cited. 
from the machine. Other studies [6-8] have found that the diaphragm of patients began to atrophy after 18 hours of mechanical ventilation treatment and became the cause of delayed weaning. Khemani et al. [9] studied 409 children treated with mechanical ventilation in PICU and analyzed the influencing factors of extubating failure. And the results showed that 43 (8.3\%) children were reintubated within 48 hours after extubating, about $35 \%$ had diminished respiratory muscle strength at extubating $\left(\right.$ aPiMax $\left.\leq 30 \mathrm{cmH}_{2} \mathrm{O}\right)$. The risk of reintubation was three times that of children with fair respiratory muscle strength (aPiMax $\left.>30 \mathrm{cmH}_{2} \mathrm{O}\right)(14 \%$ vs $5.5 \%$; $=0.006)$. Respiratory muscle weakness is a cause of difficulty in weaning mechanically ventilated children and an independent risk factor for reintubation [10-12]. How to improve respiratory muscle strength, improve respiratory function, and achieve early weaning is the key goal of PICU. It is related to the long-term prognosis and quality of life of children. Early and effective implementation of pulmonary rehabilitation can reduce the infection rate, shorten the time of mechanical ventilation, and improve respiratory function [13-15].

In 2013, American Thoracic Association (ATS) and European Respiratory Association (ERS) proposed a new definition of lung rehabilitation: "Lung rehabilitation (pulmonary rehabilitation, PR) is a comprehensive intervention program based on a comprehensive assessment of patients and tailor-made". It included but not limited to exercise training, education, and behavioral changes. The aim is to improve the physiological function and psychological environment of patients with chronic respiratory diseases, and to encourage patients to practice healthy behaviors for a long time [16-18]. With the promotion and application of lung rehabilitation, the efficacy of lung rehabilitation in chronic respiratory diseases has been confirmed. Lung rehabilitation is mainly used in chronic respiratory diseases, which can improve the physical and mental health of patients with chronic respiratory diseases and promote patients to improve their health behavior. As a comprehensive and comprehensive rehabilitation intervention, pulmonary rehabilitation is only carried out in chronic respiratory diseases, while acute severe respiratory diseases need to restore respiratory function as soon as possible and optimize the clinical outcome. Therefore, it is necessary to carry out corresponding studies to explore the feasibility and effect of lung rehabilitation in acute severe diseases.

The roadmap of this paper is organized as follows: Section 2 introduces early lung rehabilitation and principal component analysis method. Section 3 introduces the data collection of children with mechanical ventilation, and the principal component analysis method of functional data is used to analyze the collected functional data for children with mechanical ventilation. In Section 4, the structured graded pulmonary rehabilitation for children with mechanical ventilation is elaborated, according to the results of the principal component analysis method. Finally, the conclusion is given in Section 5.

\section{Related Work}

\subsection{Early Lung Rehabilitation}

The latest version of the lung rehabilitation statement proposes to expand the scope of use of lung rehabilitation, further clarify the effect of lung rehabilitation on critically ill patients and explore the adjustment of lung rehabilitation program according to the disease [16]. The research of Moss et al. [19-21] has shown that the intervention of early respiratory rehabilitation can slow down respiratory muscle atrophy and significantly shorten the time of mechanical ventilation and ICU stay. The metaanalysis of Orona et al. [22-24] included 28 studies on the effect of inspiratory muscle training on ICU patients. Compared with the control group, the inspiratory muscle strength and expiratory muscle strength of the patients with inspiratory muscle training (IMT) were significantly increased. And the length of hospital stays, and mechanical ventilation time were shorter than those of the control group. The results of randomized controlled trials conducted showed that $71 \%$ of IMT patients were weaned successfully, which was significantly better than that of the control group (47\%). Effective respiratory muscle exercise 
can have high respiratory muscle strength and endurance, promote the reconstruction and recovery of pulmonary function in patients with mechanical ventilation, improve the success rate of weaning, reduce the risk of secondary intubation and the time of mechanical ventilation. Pehlivan et al. [25-27] carried out lung rehabilitation treatment for 39 patients who received lung transplantation 3 weeks before operation. The results showed that the 6-minute walking distance, physical function, and emotional role parameters of the simplified quality of life questionnaire were significantly improved after rehabilitation treatment. Yohannes et al. [28-30] enrolled 165 patients with chronic obstructive disease with an average age of 72 and completed an 8-week community lung rehabilitation program that included aerobics and education programs and were followed up for two years. The study explores the effects of 8-week pulmonary recovery on respiratory function, anxiety, depression and quality of life after two years. The results showed that an effective 8-week pulmonary recovery program could continuously improve patients' anxiety and quality of life over a two-year period.

For adult lung rehabilitation, the corresponding research has been carried out. Wang et al. [31-33] constructed an early lung rehabilitation program for adult patients with mechanical ventilation and evaluated the clinical effect. According to the patient's sedation score and oxygenation index, the program is divided into four levels. It includes posture management, respiratory muscle training, psychological support and other four dimensions. There are great differences in physiology between children and adults. So, it is necessary to construct a lung rehabilitation program in line with the physiological characteristics of children. Lang et al. [34-36] put forward comprehensive rehabilitation strategies for children with mechanical ventilation from the aspects of posture management, motor function recovery, respiratory muscle training, sleep management, and psychological support. But they lacked specific evaluation and intervention time. And there was no specific explanation to the implementer. Wang et al. [37-39] performed individual respiratory rehabilitation on 23 children who were treated with mechanical ventilation in PICU. The results showed that respiratory rehabilitation had significant significance in shortening intubation time. However, the program only involved respiratory muscle training. And it did not pay attention to the psychological status of children. The treatment experience of PICU brings

anxiety, fear and other negative emotions to the children. And all the children have different degrees of post-traumatic stress after discharge, which has an impact on their study and life [40]. Paying attention to the psychological state of children and giving comfort, support and encouragement can alleviate the above symptoms and optimize the clinical outcome.

To sum up, at present, there are few studies on the rehabilitation of children's mechanical ventilation respiratory function. There are no relevant guidelines and operating norms, the existing intervention methods are single, and there is a lack of appropriate evaluation indicators. At present, a systematic and scientific lung rehabilitation program has not been established.

\subsection{Principal Component Analysis}

The main purpose of the principal component analysis method is to explain most of the information in the original data with fewer variables, that is, it is expected that many highly correlated variables in the hands will be transformed into unrelated variables, which can be selected from less than the original data. But several new variables that can explain most of the original data information are the so-called principal components, and which are the comprehensive indicators we use to explain the data.

Let $X=\left(X_{1}, X_{2}, \cdots, X_{p}\right)$ is a p-dimensional random vector, mean vector $E(X)=\mu$, covariance matrix $\operatorname{Var}(X)=\sum$. The linear transformation of $X$ is as follows. 
$\mathbf{X}:\left\{\begin{array}{c}f_{1}=\alpha_{1}^{T} X=\alpha_{11} X_{1}+\alpha_{12} X_{2}+\cdots+\alpha_{1 p} X_{p} \\ f_{2}=\alpha_{2}^{T} X=\alpha_{21} X_{1}+\alpha_{22} X_{2}+\cdots+\alpha_{2 p} X_{p} \\ \cdots \\ f_{p}=\alpha_{p}^{T} X=\alpha_{p 1} X_{1}+\alpha_{p 2} X_{2}+\cdots+\alpha_{p p} X_{p}\end{array}\right.$

where $\alpha_{i}=\left(\alpha_{i 1}, \alpha_{i 2}, \cdots, \alpha_{i p}\right)^{T}, i=1,2, \cdots, p$. So,

$\operatorname{Var}\left(f_{i}\right)=\alpha_{i}^{T} \sum \alpha_{i}, i=1,2, \cdots, p$

$\operatorname{Cov}\left(f_{i}, f_{j}\right)=\alpha_{i}^{T}, i, j=1,2, \cdots, p$

If the first principal component is not enough to represent most of the information of the original $p$ variables, consider $f_{2}$. In order to make $f_{2}$ with the maximum interpretation ability for the part of the information that is not explained by $f_{1}$ in the original information, it is to find $\alpha_{2}$ to maximize $\operatorname{Var}\left(f_{2}\right)$ under the condition of double constraints.

$\operatorname{Cov}\left(f_{2}, f_{1}\right)=\alpha_{2}^{T} \sum \alpha_{1}=0, \alpha_{2}^{T} \alpha_{2}=1$

The corresponding $f_{2}$ is called as the second principal component of $X$. Similarly, the third principal component, the fourth principal component can be obtained.

\section{Principal Component Analysis for Functional Data of Children with Pulmonary Rehabilitation}

\subsection{Data Collection of Children with Mechanical Ventilation}

\subsubsection{Data Collection}

This study is a non-simultaneous control study. Using convenient sampling method, 30 children with mechanical ventilation treated in PICU of the affiliated Children's Hospital of Nanjing Medical University from January to December 2018 and January to December 2019 were selected as subjects. Among them, 15 children included in 2018 were given routine rehabilitation care, while those who met the inclusion criteria were given structured graded lung rehabilitation program in 2019 as the experimental group.

Inclusion criteria: 13 years old $\leq$ age $\leq 18$ years old; 2 mechanical ventilation time $\geq 24$ hours; exclusion criteria: (1) neuromuscular diseases caused by genes; (2) cognitive abnormalities or developmental retardation; (3) multiple fractures; (4) contraindications of other lung rehabilitation therapy. This study is a non-simultaneous randomized controlled study. 15 children who met the inclusion criteria from January to December 2018 were selected as the control group, and 15 children who met the inclusion criteria from January to December 2019 were selected as the experimental group.

\subsubsection{Treatment and Intervention Method}

In the experimental group, the structured graded lung rehabilitation program was given based on routine treatment and nursing after mechanical ventilation for 24 hours. Every morning, the attending doctor, responsible nurse, rehabilitation doctor and therapist make rounds to evaluate the patient's condition, airway and muscle strength one by one. After the doctor has issued the corresponding doctor's order, the responsible nurse carried out early lung rehabilitation and records for the child according to the rehabilitation plan. The researchers were responsible for the supervision and management of the whole process. During the implementation of lung rehabilitation, they closely monitored the vital signs of children, and formulated safety principles. If the fluctuation of vital signs more than $20 \%$ of the normal range, or if the child appears pale, dizziness, chest tightness, and palpitations, it will stop immediately. The whole process of lung rehabilitation was dynamically evaluated and managed. The content of daily 
rehabilitation was timely adjusted according to the condition and tolerance of the children. And the principle of individual nursing was followed.

In the control group, routine rehabilitation nursing was given based on symptomatic treatment. That is water pillow was used to protect sacro-coccyx skin, turn over and pat the back once in 2 hours, suck sputum in time or as needed according to doctor's advice. And the ventilator pipeline nursing is done. The turn-over pad and soft pillow are utilized to change position every 2 hours, and the soft pillow is used to prevent foot drop. According to the recovery of children, children are assisted to sit up training and bedside standing training.

\subsection{Principal Component Analysis of Functional Data for Children with Mechanical Ventilation}

The dimensionality reduction of functional data is performed by the principal component basis expansion and truncation of $X_{i}(t)$. The specific operation is as the following. At first, the observed discrete data must be functionalized, and each function curve is regarded as a sample curve to perform function principal component analysis. Let the continuous curve be $X_{i}(t), i=1,2, \cdots, n$, and $i$ represents the $i$-th observation. The principal components of each curve are as the following formula.

$\xi_{i}=\int \varphi(t) X_{i}(t) d t, i=1,2, \cdots, n$

where $\varphi(t)$ is the weight function. The function value $X_{i j}$ corresponds to the data $X_{i j} j=1,2, \cdots, n$ in the classical multivariate principal component analysis. The solution of functional principal components is similar to the case of classical principal component analysis, and the maximization problem is solved under certain restricted conditions.

$$
\begin{aligned}
& \max \frac{1}{n} \sum_{i=1}^{n} \xi_{i 1}^{2}=\max \frac{1}{n} \sum_{i=1}^{n}\left[\int X_{i}(t) \varphi_{1}(t) d t\right]^{2} \\
& \text { s.t. }\left\|\varphi(t)^{2}\right\|=\int\left[\varphi_{1}(t)\right]^{2} d t=1
\end{aligned}
$$

If there is one that satisfies this constraint and reaches the maximum, the corresponding $\xi_{i 1}$ is called the first principal component of $X_{i}(t)$, which is the projection of $X_{i}(t)$ in the direction $\varphi(t)$, and $\varphi(t)$ is the characteristic function (weight function) of the first principal component. Similarly, when the solution of the $k$-th principal component meets the following constraints, the maximization problem is solved.

$\max \frac{1}{n} \sum_{i=1}^{n} \xi_{i k}^{2}=\max \frac{1}{n} \sum_{i=1}^{n}\left[\int X_{i}(t) \varphi_{k}(t) d t\right]^{2}$

From the above construction process, it is found that multiple weight functions satisfy the orthogonal constraint conditions.

$\int \varphi_{h}(t) \varphi_{l}(t) d t=0, h \neq l$

In order to get the weight function of functional principal component analysis, the covariance function of the function should be used to find the coefficient of the weight function, according to the covariance function.

$G_{X}(s, t)=\frac{1}{n-1} \sum_{i=1}^{n} X_{i}(t) X_{i}(s)$

The characteristic equation of the weight function in functional principal component analysis can be obtained. 
$\int G_{X}(s, t) \varphi(t) d t=\lambda \varphi(s)$

where $\lambda$ is the characteristic value of $G_{X}(s, t)$, and $\varphi(s)$ is the characteristic function corresponding to the characteristic value. Define $G \varphi(s)=\int G_{X}(s, t) \varphi(t) d t$, where $G \varphi(s)$ is the integral transformation of $G_{X}(s, t)$ as the kernel, and $G$ is called the covariance operator. Then $G \varphi(s)=\lambda \varphi(s)$. The function $X_{i}(t)$ can be expressed as a linear combination of basic functions.

$X_{i}(t)=\sum_{k=1}^{K} \xi_{i k} \varphi_{k}(t)$

Thus, the covariance function can be written as the following.

$G_{X}(s, t)=\frac{1}{n} \sum_{i=1}^{n}\left[\sum_{k=1}^{K} \xi_{i k} \varphi_{k}(s)\right]\left[\sum_{k=1}^{K} \xi_{i k} \varphi_{k}(t)\right]=\frac{1}{n} \varphi^{T}(s) \xi^{T} \xi \varphi(t)$

The linear combination of the basic functions of the weight function is expressed as.

$\varphi(t)=\sum_{k=1}^{K} b_{k} \varphi_{k}(t)=\Phi^{T}(t) b, b=\left(b_{1}, b_{2}, \cdots, b_{k}\right)$

The parameter vector is estimated. And the characteristic equation can be written as the following.

$\frac{1}{n} \xi^{T} \xi W b=\lambda b$, where $W=\int \varphi(s)^{T} \varphi(t) d t$

From this, the weight function coefficient vector $\mathrm{b}$ can be obtained, and then the principal component weight function can be obtained.

\section{Structured Graded Pulmonary Rehabilitation for Children with Mechanical Ventilation}

A total of 24 children who were treated with mechanical ventilation in PICU from January to December 2018 were reviewed, excluding cases of age $<3$ years $(n=4)$, death $(n=3)$ and gene-induced neuromuscular diseases $(n=4)$. A total of 15 children met the inclusion criteria, including 7 males and 8 females, with an average age of 6.67 years. The diseases were composed of respiratory system $(n=7)$, nervous system $(n=4)$, circulatory system $(n=3)$ and trauma $(n=1)$. The structured graded lung rehabilitation program was formally implemented in PICU from January to December 2019. According to the inclusion criteria, a total of 17 children received lung rehabilitation, in which 2 cases dropped out because their parents gave up treatment. Finally, 15 children were included, which includes 10 males and 5 females, with an average age of 5.57 years old. The diseases were composed of respiratory system $(n=7)$, nervous system $(n=4)$, circulatory system $(n=3)$ and trauma $(n=1)$.

In the research, a total of 518 times of lung rehabilitation were performed, during which there were no unplanned extubating, fall, bed fall and other adverse events. And there were no abnormal fluctuations in heart rate, blood pressure and transcutaneous oxygen saturation. From the above analysis, we get the following rehabilitation grading treatment strategy. Tab. 1 shows the basic rehabilitation measure. The basic measure applies to lung rehabilitation for all children with invasive mechanical ventilation.

On the basis of the basic rehabilitation measure, the respiratory muscle training and full range joint motion plan were added to the lung rehabilitation measures. And the primary lung rehabilitation measure was formed. It is showed in Tab. 2.

Based on the primary rehabilitation measure, the resistance training, psychological support, and motor function exercise are added to the lung rehabilitation measures. And the secondary lung rehabilitation measure is formed and showed in Tab. 3. 
Table 1: Basic lung rehabilitation strategy

\begin{tabular}{|c|c|c|}
\hline Grade & Assessment & Rehabilitation intervention \\
\hline \multirow[t]{3}{*}{$\begin{array}{l}\text { Basic } \\
\text { measure }\end{array}$} & $\begin{array}{l}\text { All children with severe } \\
\text { pneumonia undergoing } \\
\text { mechanical ventilation who } \\
\text { meet the inclusion and } \\
\text { exclusion criteria }\end{array}$ & $\begin{array}{l}\text { 1. Posture management } \\
\text { (1) keep the head of the bed raised } 30^{\circ} \text { when the condition permits, } \\
\text { and turn over every } 2 \text { hours. } \\
\text { (2) keep the body in the functional position and avoid limb } \\
\text { dysfunction caused by long-term bedridden. }\end{array}$ \\
\hline & & $\begin{array}{l}\text { 2. Airway clearance } \\
\text { (1) promoting expectoration: chest percussion, humidification and } \\
\text { expectoration, atomization inhalation and postural drainage. } \\
\text { (2) standardized and effective sputum suction, complete sputum } \\
\text { suction with fiberoptic bronchoscope if necessary, and use } \\
\text { artificial airway with subglottic attraction for subglottic suction. }\end{array}$ \\
\hline & & $\begin{array}{l}\text { 3. Other } \\
\text { Oral care, sedation and analgesia, drug therapy, nutritional } \\
\text { support, restricted fluid replacement, etc. }\end{array}$ \\
\hline
\end{tabular}

Table 2: Primary lung rehabilitation strategy

\begin{tabular}{|c|c|c|}
\hline Grade & Assessment & Rehabilitation intervention \\
\hline $\begin{array}{l}\text { Primary } \\
\text { measure }\end{array}$ & $\begin{array}{l}\text { Richmond restlessness } \\
\text { sedation score } \\
\text { (Richmond Agitation- } \\
\text { Sedution Scale, RASS) } \\
\text { score } \leq-2 \text { or RASS } \\
\text { score }=2 \text {, or } \\
\text { oxygenation index }(\mathrm{OI}) \leq \\
200 \mathrm{mmHg} \text {, or } \\
\text { circulatory instability } \\
\text { can be maintained by } \\
\text { medication, or muscle } \\
\text { strength }<2\end{array}$ & $\begin{array}{l}\text { 1. Posture management } \\
\text { Routine change of posture, raising the head of the bed } 5^{\circ}-10^{\circ} \text { every } \\
\text { day, twice a day, } 10-15 \mathrm{~min} / \text { times if the disease permits } \\
\text { 2. Airway clearance } \\
\text { In the absence of contraindications, high-frequency vibration } \\
\text { expectoration or expectoration machine is used for children, twice a } \\
\text { day, } 10 \text {-20min/ times, to remove airway secretions and avoid } \\
\text { airway blockage to further aggravate the disease. } \\
\text { 3. Respiratory muscle training } \\
\text { Passive respiratory muscle training is performed for children, hands } \\
\text { are massaged by rolling and kneading methods to relax respiratory } \\
\text { muscle groups, and plucking method is used to stimulate } \\
\text { respiratory muscle groups. Combined with the respiratory } \\
\text { frequency of the children, do the separation manipulation and chest } \\
\text { passive movement of the upper and lower chest, passively move the } \\
\text { thoracic and abdominal muscles and stretch the intercostal muscles, } \\
\text { and slow down the respiratory muscle atrophy and weakness } \\
\text { caused by long-term bed rest and mechanical ventilation. } \\
\text { 4. Full range joint motion } \\
\text { Passive movements of large joints of the whole body (flexion, } \\
\text { extension, adduction, abduction, internal rotation, external } \\
\text { rotation), each movement is repeated } 10 \text { times, twice/d), including } \\
\text { shoulder joint, elbow joint, wrist joint, hip joint, knee joint, ankle } \\
\text { joint, etc. }\end{array}$ \\
\hline
\end{tabular}


Table 3: Secondary lung rehabilitation strategy

\begin{tabular}{|c|c|c|}
\hline Grade & Assessment & Rehabilitation intervention \\
\hline \multirow[t]{6}{*}{$\begin{array}{l}\text { Secondary } \\
\text { measure }\end{array}$} & \multirow[t]{6}{*}{$\begin{array}{l}-1 \leq \mathrm{RASS} \leq 1 \text { and } \\
200 \mathrm{mmHg} \leq \mathrm{O} \leq \\
300 \mathrm{mmHg} \text { or } \\
\text { circulation is } \\
\text { relatively stable, or } 2 \\
<\text { muscle strength } \leq 3\end{array}$} & $\begin{array}{l}\text { 1. Posture management } \\
\text { If the condition permits, raise the head of the bed } 10^{\circ}-15^{\circ} \text { every day, } \\
\text { and assist the patient to take the semi-sitting seat as soon as possible } \\
\text { and gradually transition to the sitting position, twice a day for } 10- \\
15 \text { minutes. }\end{array}$ \\
\hline & & $\begin{array}{l}\text { 2. Respiratory muscle training } \\
\text { (1) Abdominal breathing: instruct the child to breathe through the } \\
\text { abdomen, dilate the abdomen as much as possible when inhaling, } \\
\text { and contract the abdomen inward as much as possible when } \\
\text { exhaling, twice a day, } 10-15 \text { min. } \\
\text { (2) Lip contraction breathing: tell the child to hold his breath for } 3 \mathrm{~s} \\
\text { after taking a deep breath, and his lips shrink into a whistling shape, } \\
\text { so that the gas can be exhaled slowly through the narrowed mouth. } \\
\text { The ratio of inspiratory to exhaled time is } 1: 2 \text { or } 1: 3.2 \text { times/day, } \\
20 \text { groups/time. } \\
\text { (3) Active circulatory breathing technique: inhale deeply, then } \\
\text { exhale hard to loosen and remove the secretions in the peripheral } \\
\text { airway, and when the secretions enter the atmospheric tract, the } \\
\text { sputum is excreted through gasping or coughing. } 2 \text { times/day, } \\
20 \text { groups/time. }\end{array}$ \\
\hline & & $\begin{array}{l}\text { 3. Exercise of motor function } \\
\text { (1) Assist exercise: tell the children to slowly lift one side of the } \\
\text { upper limb/lower limb to reach the maximum value of their existing } \\
\text { ability and put it down slowly after insisting on } 5 \mathrm{~s}-10 \mathrm{~s} \text {. In this } \\
\text { process, the trainer can give the child a supporting strength to help } \\
\text { the children complete the lifting and falling movements of the upper/ } \\
\text { lower limbs. } 2 \text { times/day, } 10 / \text { times/limbs. } \\
\text { (2) Anti-gravity movement: based on power-assisted sports training, } \\
\text { gradually transition to break away from the power-assisted support, } \\
\text { and complete the above-mentioned movements alone, and the speed is } \\
\text { faster than that of power-assisted sports. } 2 \text { times/day, } 15 / \text { times/limbs. }\end{array}$ \\
\hline & & $\begin{array}{l}\text { 4. Resistance training } \\
\text { Hold the strength ball or rubber ball in hand, exercise the forearm } \\
\text { flexor muscle group and forearm extensor group; use elastic band to } \\
\text { stretch muscle, increase muscle strength, train pectoralis major and } \\
\text { biceps femoris. } 2 \text { times per day, } 20 \text { times per day. }\end{array}$ \\
\hline & & 5. Psychological support \\
\hline & & $\begin{array}{l}\text { 1. Try to establish an effective way of communication with the child: } \\
\text { use gestures, lip language, nodding or shaking your head, prompt } \\
\text { cards and other expressions to actively build trust with the child. } \\
\text { 2. Evaluate the psychological status of children in time, such as } \\
\text { depression, anxiety, fear, etc., and give corresponding } \\
\text { psychological intervention in time. }\end{array}$ \\
\hline
\end{tabular}


On the basis of the secondary rehabilitation measure, we added the family health education plan to the lung rehabilitation measures. And the three-level lung rehabilitation measure is formed and showed in Tab. 4.

Table 4: Three-level lung rehabilitation strategy

\begin{tabular}{|c|c|c|}
\hline Grade & Assessment & Rehabilitation intervention \\
\hline $\begin{array}{l}\text { Three-level } \\
\text { measure }\end{array}$ & $\begin{array}{l}-1 \leq \mathrm{RASS} \leq 1 \text { and } \\
300 \mathrm{mmHg} \leq \mathrm{OI} \leq \\
400 \mathrm{mmHg} \text { or } \\
\text { circulatory stability, } \\
\text { or muscle strength }>3\end{array}$ & $\begin{array}{l}\text { 1. Posture management } \\
\text { When the condition of the child permits, gradually transition from } \\
\text { sitting position to bedside sitting, and realize bed-chair transfer. The } \\
\text { training time and intensity depend on the tolerance of the child. } \\
\text { 2. Respiratory muscle exercise } \\
\text { 1. Ball blowing training: use small balls or whistles to increase } \\
\text { inspiratory muscle resistance and workmanship, and exercise } \\
\text { inspiratory muscle strength. } \\
\text { 2. abdominal pressure training: } 200 \mathrm{~g}, 500 \mathrm{~g} \text { and } 800 \mathrm{~g} \text { salt bags were } \\
\text { placed in the abdomen as appropriate to increase the pressure of } \\
\text { inspiratory and expiratory muscles during abdominal breathing } \\
\text { and improve respiratory function. } 2 \text { times per day, } 10-15 \text { times } \\
\text { per day. } \\
\text { 3. Exercise of motor function } \\
\text { 1. Anti-gravity training: hip bridge exercise: abdominal force, } \\
\text { buttocks lifted upward from the bed surface, increasing } \\
\text { abdominal muscle and lumbar dorsal muscle strength; bedside } \\
\text { sitting leg lifting training: assisting children to sit at the } \\
\text { bedside, lower limbs drooping, doing unilateral lower limb } \\
\text { lifting, flexion and stretching alone (same as above). } 2 \text { times/ } \\
\text { day, } 10-15 / \text { time/limb. } \\
\text { 2. Resistance training: the children's upper and lower limbs or both } \\
\text { upper limbs were loaded with } 300 \mathrm{~g}, 600 \mathrm{~g} \text { and } 1000 \mathrm{~g} \text { sandbags. } \\
2 \text { times/day, } 10-15 / \text { time/limb. } \\
\text { 3. When the muscle strength is } \geq 4 \text {, it can help the child to stand by } \\
\text { the bed. } 2 \text { times a day, } 5-10 \text { minutes, depending on the tolerance } \\
\text { of the child. } \\
\text { 4. Psychological support } \\
\text { Give continuous psychological support and intervention to children. } \\
\text { 5. Family health education } \\
\text { Explain the necessity of early rehabilitation to family members, } \\
\text { introduce the methods of home rehabilitation according to the } \\
\text { situation of children, work out individual home rehabilitation } \\
\text { programs with children and their parents, and follow up regularly. }\end{array}$ \\
\hline
\end{tabular}

\section{Conclusion}

Based on principal component analysis of functional pneumonia data, this paper constructed a structured graded lung rehabilitation program for children with invasive mechanical ventilation and carried out graded lung rehabilitation nursing for children according to their severity and functional status, to improve their 
respiratory function, shorten the time of mechanical ventilation and PICU hospitalization, and reduce their anxiety. Scientific evaluation and dynamic monitoring ensure the safety of program implementation and promote the prognosis and prognosis of the disease. This study provides a reference basis for the formulation of lung rehabilitation guidelines for children with mechanical ventilation. And It has important reference significance for clinical pulmonary rehabilitation.

Acknowledgement: We thank the director of rehabilitation medicine department in the children's hospital of Nanjing medical university (Jian Tang).

Funding Statement: This work is supported by Science and Technology Development Fund of Nanjing Medical University (No. NJMUB2019188). Ling Zhang received the grant and the URLs to sponsors' websites is https://www.njmu.edu.cn.

Conflicts of Interest: The authors declare that they have no conflicts of interest to report regarding the present study. Lei Ren and Jing $\mathrm{Hu}$ are the co-first authors.

\section{References}

[1] A. E. Turnbull, A. Rabiee and W. E. Davis, "Outcome measurement in ICU survivorship research from 1970 to 2013: A scoping review of 425 publications," Critical care medicine, vol. 44, no. 7, pp. 1267-1281, 2016.

[2] Y. Ren, J. Qi, Y. Cheng, J. Wang and O. Asama, "Digital continuity guarantee approach of electronic record based on data quality theory," Computers, Materials \& Continua, vol. 63, no. 3, pp. 1471-1483, 2020.

[3] Y. Xue, P. Xu and L. Shan, "Progress in respiratory evaluation and treatment of children with invasive mechanical ventilation," Chinese Journal of Contemporary Pediatrics, vol. 21, no. 1, pp. 94-99, 2019.

[4] J. Wang, W. Chen, L. Wang, Y. J. Ren and R. S. Sherratt, "Blockchain-based data storage mechanism for industrial Internet of Things," Intelligent Automation \& Soft Computing, vol. 26, no. 5, pp. 1157-1172, 2020.

[5] Ye. Wang, Q. Qian, S. Wang, X. Wang and B. Fang, "Cause analysis and prognosis follow-up of long-term inpatients with PICU," China Pediatric Emergency Medicine, vol. 22, no. 3, pp. 553-556, 2015.

[6] S. K. Powers, A. N. Kavazis and S. Levine, "Prolonged mechanical ventilation alters diaphragmatic structure and function," Critical Care Medicine, vol. 37, no. 10, pp. 347-353, 2009.

[7] C. Ge, Z. Liu, J. Xia and L. Fang, "Revocable identity-based broadcast proxy re-encryption for data sharing in clouds," IEEE Transactions on Dependable and Secure Computing, vol. 19, no. 3, pp. 1-10, 2019.

[8] T. Li, Y. Ren and J. Xia, "Blockchain queuing model with non-preemptive limited-priority," Intelligent Automation \& Soft Computing, vol. 26, no. 5, pp. 1111-1122, 2020.

[9] R. G. Khemani, T. Sekayan and J. Hotz, "Risk factors for pediatric extubation failure: the importance of respiratory muscle strength," Critical Care Medicine, vol. 45, no. 8, pp. 798-805, 2017.

[10] L. R. Cui, M. Laporte and M. Civitello, "Physical and occupational therapy utilization in a pediatric intensive care unit," Journal of Critical Care, vol. 40, no. 5, pp. 716-721, 2017.

[11] Y. Ren, Y. Leng, J. Qi, K. S. Pradip, J. Wang et al., "Multiple cloud storage mechanism based on blockchain in smart homes," Future Generation Computer Systems, vol. 115, pp. 304-313, 2021.

[12] C. P. Ge, W. Susilo, J. Baek, Z. Liu, J. Xia et al., "Revocable attribute-based encryption with data integrity in clouds," IEEE Transactions on Dependable and Secure Computing, vol. 21, no. 3, pp. 1-12, 2021.

[13] W. Liu, X. Mu and X. Wang, "Effects of comprehensive pulmonary rehabilitation therapy on pulmonary functions and blood gas indexes of patients with severe pneumonia," Experimental and Therapeutic Medicine, vol. 16, no. 7, pp. 1953-1957, 2018.

[14] W. Zhao, J. Liu, H. Guo and T. Hara, "ETC-IoT: Edge-node-assisted transmitting for the cloud-centric internet of things," IEEE Network, vol. 32, no. 3, pp. 101-107, 2018.

[15] Y. Ren, J. Qi, Y. Liu, J. Wang and G. Kim, "Integrity verification mechanism of sensor data based on bilinear map accumulator," ACM transactions on Internet Technology, vol. 21, no. 1, pp. 1-19, 2021. 
[16] W. D. Travis, U. Costabel and D. M. Hansell, "An official American thoracic society/European respiratory society statement: Update of the international multidisciplinary classification of the idiopathic interstitial pneumonias," Am J Respir Crit Care Med, vol. 188, no. 6, pp. 733-748, 2013.

[17] L. Fang, Y. Li, X. Yun, Z. Wen, S. Ji et al., "THP: A novel authentication scheme to prevent multiple attacks in SDN-based IoT network," IEEE Internet of Things Journal, vol. 7, no. 7, pp. 5745-5759, 2020.

[18] J. Xu, L. Wei, A. Wang, Y. Zhang, F. Zhou et al., "Dynamic fully homomorphic encryption-based Merkle tree for lightweight streaming authenticated data structures," Journal of Network and Computer Applications, vol. 107, no. 8, pp. 113-124, 2018.

[19] M. Moss, A. C. Nordon and D. Malone, "A randomized trial of an intensive physical therapy program for patients with acute respiratory failure," American Journal of Respiratory \& Critical Care Medicine, vol. 193, no. 10, pp. 1101-1120, 2016.

[20] Y. J. Ren, Y. Leng, Y. Cheng and J. Wang, "Secure data storage based on blockchain and coding in edge computing," Mathematical Biosciences and Engineering, vol. 16, no. 4, pp. 1874-1892, 2019.

[21] C. Ge, W. Susilo, Z. Liu, J. Xia, P. Szalachowski et al., "Secure keyword search and data sharing mechanism for cloud computing," IEEE Transactions on Dependable and Secure Computing, vol. 20, no. 4, pp. 1, 2020.

[22] V. Orona, S. Tefannie, S. Abatini, U. Mberto, A. Maqbali et al., "Inspiratory muscle rehabilitation in critically ill adults: A systematic review and meta-analysis," American Thoracic Society, vol. 17, no. 11, pp. 1296-1310, 2018.

[23] Y. Mao, J. Zhang, H. Qi and L. Wang, "DNN-MVL: DNN-multi-view-learning-based recover block missing data in a dam safety monitoring system," Sensors, vol. 19, no. 13, pp. 1-22, 2019.

[24] J. Xiong, M. Zhao, M. Bhuiyan, L. Chen and Y. Tian, "An AI-enabled three-party game framework for guaranteed data privacy in mobile edge crowdsensing of IoT," IEEE Transactions on Industrial Informatics, vol. 17, no. 2, pp. 922-933, 2021.

[25] E. Pehlivan, A. Balc and L. Kilic, "Preoperative pulmonary rehabilitation for lung transplant: Effects on pulmonary function, exercise capacity, and quality of life," Experimental and Clinical Transplantation, vol. 16, no. 6, pp. 455-460, 2018.

[26] Y. Tian, Z. Wang, J. Xiong and J. Ma, "A blockchain-based secure key management scheme with trustworthiness in DWSNs," IEEE Transactions on Industrial Informatics, vol. 16, no. 9, pp. 6193-6202, 2020.

[27] Y. Ren, F. Zhu, K. S. Pradip, J. Wang, T. Wang et al., "Data query mechanism based on hash computing power of blockchain in Internet of Things Sensors," Sensors, vol. 20, no. 1, pp. 1-22, 2020.

[28] A. M. Yohannes, S. Dryden and R. Casaburi, "Long-term benefits of pulmonary rehabilitation in COPD patients: a 2-year follow-up study," Chest, vol. 20, no. 1, pp. 38-51, 2020.

[29] L. Gong, B. Yang, T. Xue, J. Chen and W. Wang, "Secure rational numbers equivalence test based on threshold cryptosystem with rational numbers," Information Sciences, vol. 466, no. 10, pp. 44-54, 2018.

[30] J. Y. Ren, Y. Liu, S. Ji, A. K. Sangaiah and J. Wang, "Incentive mechanism of data storage based on blockchain for wireless sensor networks," Mobile Information Systems, vol. 2018, no. 8, pp. 1-10, 2018.

[31] L. Wang, F. L. Xu and G. Liu, "Study on the construction and application of early lung rehabilitation grading scheme for mechanically ventilated patients," Chinese Journal of Nursing, vol. 8, no. 3, pp. 35-41, 2020.

[32] J. Wang, Y. Q. Yang, T. Wang, R. S. Sherratt and J. Y. Zhang, "Big data service architecture: A survey," Journal of Internet Technology, vol. 21, no. 2, pp. 393-405, 2020.

[33] G. Xu, X. Li, L. Jiao, W. Wang, A. Liu et al., "BAGKD: A batch authentication and group key distribution protocol for VANETs," IEEE Communications Magazine, vol. 58, no. 7, pp. 35-41, 2020.

[34] L. G. Lang, J. M. Wang, C. Pan, Y. Xue, L. Shan et al., "Rehabilitation strategy for children with invasive mechanical ventilation," Chinese Journal of Rehabilitation Medicine, vol. 35, no. 5, pp. 635-639, 2020.

[35] Y. Ren, K. Zhu, Y. Gao, J. Xia, S. Zhou et al., "Long-term preservation of electronic record based on digital continuity in smart cities," Computers, Materials \& Continua, vol. 66, no. 3, pp. 3271-3287, 2021.

[36] G. Xu, Y. Zhao, L. Jiao, M. Feng, Z. Ji et al., "TT-SVD: An efficient sparse decision making model with two-way trust recommendation in the AI enabled IoT systems," IEEE Internet of Things Journal, vol. 20, no. 6, pp. 1-12, 2020. 
[37] S. J. Wang, H. Zhou, W. Chen and G. Lu, "Early respiratory rehabilitation for critically ill children with mechanical ventilation," Chinese Pediatric Emergency Medicine, vol. 20, no. 2, pp. 110-113, 2020.

[38] Y. Tian, Q. Li, J. Hu and H. Lin, "Secure limitation analysis of public-key cryptography for smart card settings," World Wide Web-internet and Web Information Systems, vol. 23, no. 2, pp. 1423-1440, 2020.

[39] G. Q. Xu, X. Xie, S. Huang, J. Zhang, L. Pan et al., "JSCSP: A novel policy-based XSS defense mechanism for browsers," IEEE Transactions on Dependable and Secure Computing, vol. 20, no. 7, pp. 1-12, 2020.

[40] J. X. Chen and T. H. Ye, "Post-traumatic stress disorder of children in PICU: A review," Chinese Nursing Management, vol. 16, no. 10, pp. 1205-1209, 2015. 